\title{
CTLA4Ig inhibits T cell-dependent B-cell maturation in murine systemic lupus erythematosus
}

\author{
Masahiko Mihara, ${ }^{1,2}$ Irene Tan, ${ }^{1}$ Yelena Chuzhin, ${ }^{1}$ Bhoompally Reddy, ${ }^{1,2}$ \\ Lalbachan Budhai, ${ }^{1,2}$ Aton Holzer, ${ }^{1}$ Yun Gu, ${ }^{3}$ and Anne Davidson ${ }^{1,2}$ \\ ${ }^{1}$ Department of Medicine, \\ ${ }^{2}$ Department of Microbiology and Immunology, and \\ ${ }^{3}$ Department of Epidemiology and Social Medicine, Albert Einstein College of Medicine, Bronx, New York, USA \\ Address correspondence to: Anne Davidson, Albert Einstein College of Medicine, 1300 Morris Park Avenue, U505, \\ Bronx, New York 10461, USA. Phone: (718) 430-4107; Fax: (718) 430-8789; E-mail: davidson@aecom.yu.edu. \\ Masahiko Mihara’s present address is: Chugai Pharmaceuticals, Gotemba-shi, Shizouka, Japan. \\ Masahiko Mihara and Irene Tan contributed equally to this work.
}

Received for publication December 22, 1999, and accepted in revised form May 31, 2000.

\begin{abstract}
Long-term administration of CTLA4Ig prevents the onset of disease in systemic lupus erythematosus-prone (SLE-prone) NZB/NZW F1 mice. To determine the mechanism of this effect, we engineered an adenovirus that expresses murine CTLA4Ig. Administration of a single high dose of this virus results in long-term expression of CTLA4Ig in the serum and absence of an immune response to the adenoviral vector. We administered Ad-CTLA4Ig to 19- to 22-week-old NZB/NZW F1 mice and evaluated the effect on anti-DNA antibody-producing B cells. We show that CTLA4Ig has a beneficial effect on murine SLE for as long as it is present in the serum. This effect is associated with decreased expansion of both the IgM and IgG autoreactive B-cell population, inhibition of immunoglobulin class switching, decreased frequency and altered pattern of somatic mutation, and a marked decrease in the numbers of activated CD4-positive T cells. In contrast, intrinsic B-cell hyperreactivity and the survival of plasma cells in the bone marrow, both of which are less dependent on T-cell help, appear to be unaffected by CTLA4Ig. High-dose CTLA4Ig did not induce permanent tolerance in this autoimmune disease model. Furthermore, although the mice survived in a conventional housing facility, treatment with Ad-CTLA4Ig was immunosuppressive.
\end{abstract}

J. Clin. Invest. 106:91-101 (2000).

\section{Introduction}

Systemic lupus erythematosus (SLE) is characterized by dysregulated activation of both $\mathrm{T}$ and $\mathrm{B}$ lymphocytes with the development of autoantibodies, particularly to double-stranded DNA (dsDNA), that are critically involved in tissue damage (1). Pathogenic autoantibodies in SLE are of the IgG isotype and have acquired somatic mutations, indicating that the B cells that produce them have matured under the influence of T-cell help $(1,2)$. To initiate this type of mature humoral immune response to either foreign or selfantigen, both $\mathrm{T}$ - and $\mathrm{B}$-cell costimulatory interactions are required. The major receptor ligand pairs that are involved are $\mathrm{B} 7 / \mathrm{CD} 28$ and $\mathrm{CD} 40 / \mathrm{CD} 40 \mathrm{~L}(3,4)$. The engagement of CD28 on the T-cell surface by $\mathrm{B} 7.1$ (CD80) or B7.2 (CD86) on the surface of activated antigen-presenting cells (APCs) or B cells activates signaling pathways that promote T-cell survival and induce T-cell expression of CD40L (CD154). CD40L interacts with CD40 on the APCs, resulting in further upregulation of $\mathrm{MHC}$ and $\mathrm{B} 7$ and the release of cytokines and other inflammatory mediators $(5,6)$. The interaction of CD40L on activated $T$ cells with CD40 on antigen-specific B cells also induces B-cell proliferation and formation of germinal centers (6-8). Costimulation-dependent cell-cell interactions within the germinal center lead to B-cell maturation through immunoglobulin isotype switching, somatic mutation, clonal expansion of high-affinity B cells, terminal differentiation to plasma cells, and formation of memory B cells that express B7 and can further activate $T$ cells by acting as APCs (6-10).

Within 2-3 days after activation, $\mathrm{T}$ cells begin to produce CTLA4 (CD152), which competes with CD28 for binding to $\mathrm{B} 7.1$ and $\mathrm{B} 7.2$ and transduces a negative signal to the $\mathrm{T}$ cell that will help terminate the immune response to the inciting antigen (11). CTLA4Ig is a soluble fusion protein consisting of the extracellular domain of CTLA4 and modified CH2$\mathrm{CH} 3$ domains of IgG that no longer bind Fc receptors; it binds B7.1 and B7.2 with much higher affinity than CD28 and thus serves as an efficient competitive antagonist of the critical B7/CD28 costimulatory interaction (12). Recent reports have demonstrated the effectiveness of human CTLA4Ig in two T cell-mediated diseases, graft versus host disease and psoriasis $(13,14)$. In addition, Finck et al. have reported that long-term administration of murine CTLA4Ig to 
NZB/NZW F1 mice that spontaneously develop an SLE-like disease prevented the onset of the disease for many months (15).

This study was designed to add to our understanding of how CTLA4Ig affects an ongoing autoimmune response. We have engineered an adenovirus that expresses murine CTLA4Ig (Ad-CTLA4Ig). Administration of a single high dose of this virus to normal mice results in the long-term expression of CTLA4Ig in the serum, the absence of an immune response to the adenovirus, and the suppression of immune responses to both alloantigen and hapten (B. Reddy et al., manuscript submitted for publication). We show here that administration of high-dose Ad-CTLA4Ig to NZB/NZW F1 mice results in long-term delay in expression of high titers of anti-DNA antibodies and onset of SLE manifestations without affecting total serum immunoglobulin levels. We used serologic and molecular analysis to examine the effect of CTLA4Ig on pathogenic B cells. Our findings strongly suggest that in this autoimmune model, as in normal mice, CTLA4Ig predominantly affects the $\mathrm{T}$ cell-dependent steps of B-cell maturation. These findings have implications for potential new forms of treatment for human autoimmune diseases.

\section{Methods}

Generation of Ad-CTLA4Ig. The full-length cDNA of murine CTLA4Ig, mutated so that it no longer binds Fc receptors (obtained from J. Bradshaw, Bristol-Meyers Squibb Co.), was subcloned along with the CMV promoter into the adenovirus shuttle vector $\mathrm{p} \Delta \mathrm{E} 1 \mathrm{sp} 1 \mathrm{~A}$ (Microbix Biosystems Inc., Toronto, Ontario, Canada). The shuttle vector was cotransfected with the adenoviral vector PBHG11 (Microbix Biosystems Inc.) into 293 cells (American Type Culture Collection, Rockville, Maryland, USA), and wells demonstrating cytopathic effect were screened for CTLA4Ig production by ELISA. An adenovirus secreting high-titer CTLA4Ig was obtained from this transfection and plaque-purified. Purified adenovirus was prepared by standard techniques and then titered by plaque assay. Control adenovirus expressing $\beta$ galactosidase (Ad-LacZ) was a gift of J. Roy Chowdhury of Albert Einstein College of Medicine (AECOM).

CTLA4Ig ELISA. ELISA plates (Nalge Nunc International, Naperville, Illinois, USA) were coated with anti-murine CTLA4 (PharMingen, San Diego, California, USA) 1/500 in PBS overnight at $4^{\circ} \mathrm{C}$, blocked with $5 \% \mathrm{FCS} / 3 \% \mathrm{BSA}$ in $\mathrm{PBS}$, and then incubated sequentially for 1 hour at $37^{\circ} \mathrm{C}$ with serial dilutions of serum or cell line supernatants followed by peroxidase conjugated Fab' 2 goat anti-mouse IgG2a 1/8,000 in PBS/1\%BSA (Accurate Antibodies, Westbury, New York, USA) and ABTS substrate (Kirkegaard and Perry, Gaithersburg, Maryland, USA). Serial dilutions of a known concentration of purified CTLA4Ig were used in each plate to establish a standard curve.

Antiadenoviral antibodies. IgG antiadenoviral antibodies were measured at 21 days by ELISA, and neutralizing antiadenoviral titers were measured at 4 weeks as described previously (16).
Mice. NZB/NZW F1 females were purchased from The Jackson Laboratory (Bar Harbor, Maine, USA) and maintained in a conventional animal housing facility throughout the experiment. Mice were treated at the age of 20-22 weeks with a single intravenous injection of either low-dose (ten mice: $5 \times 10^{8} \mathrm{pfu}$ ) or high-dose (ten mice: $2 \times 10^{9} \mathrm{pfu}$ ) Ad-CTLA4Ig. Controls received either Ad-LacZ (14 mice: $\left.5 \times 10^{8} \mathrm{pfu}\right)$, mouse monoclonal IgG2a (Sigma Chemical Co., St Louis, Missouri, USA), $75 \mu$ g every 2 weeks (15 mice), or no treatment (eight mice). Mice were bled every $2-4$ weeks. Urine was tested for proteinuria by dipstick (Multistick; Fisher Scientific Co., Pittsburgh, Pennsylvania, USA) every 2 weeks. Survival splenectomies were performed at intervals after treatment. All mice that remained alive were sacrificed at 52-60 weeks.

Histology. Kidneys were embedded in paraffin, and sections were stained with hematoxylin and eosin. Frozen sections were stained with FITC anti-mouse IgG 1/150 (Cooper Biomedical, Westchester, Pennsylvania, USA) in $10 \%$ goat serum or with peroxidase conjugated anti-mouse C3 1/200 (Cappel) in 10\% goat serum followed by DAB substrate (Vector Laboratories, Burlingame, California, USA).

FACS ${ }^{\circledR}$ analysis. Spleen cells were analyzed for B- and T-cell markers using antibodies to CD4, CD8 (both from Caltag Laboratories Inc., Burlingham, California, USA), and CD19 (PharMingen). Presence of activated CD4 cells was determined by double staining with FITC-anti-CD4 (Caltag Laboratories Inc.) and PE-antiCD69 (PharMingen). Presence of naive and memory CD4 cells was determined by triple staining with FITC-anti-CD4, Cy-anti-CD44 (PharMingen), and PE-anti-CD62L (PharMingen).

Serum immunoglobulin levels. ELISA plates (Falcon Labware, Lincoln Park, New Jersey, USA) were coated with anti-mouse immunoglobulins (Cappel) overnight at $4^{\circ} \mathrm{C}$, blocked, and then incubated sequentially for 1 hour at $37^{\circ} \mathrm{C}$ with serial dilutions of serum followed by peroxidase conjugated Fab' 2 goat anti-mouse IgM or IgG $1 / 2,000$ in PBS/1\%BSA (Cappel) and ABTS substrate. Standard curves for IgM and IgG were established using $\mathrm{BALB} / \mathrm{c}$ serum and results were expressed as the titer at which maximal binding to the plate was first attained. Anti-DNA antibodies. ELISA plates (Falcon Labware) were coated with $100 \mu \mathrm{L}$ of $100 \mu \mathrm{g} / \mathrm{mL}$ salmon sperm DNA made double stranded by passage through a $45-\mu \mathrm{m}$ filter (USA Scientific, Ocala, Florida, USA). After drying, the plates were blocked and then incubated sequentially for 1 hour at $37^{\circ} \mathrm{C}$ with serial dilutions of serum or cell line supernatants followed by peroxidase conjugated $\mathrm{Fab}^{\prime} 2$ goat anti-mouse IgM or IgG $1 / 2,000$ in PBS/1\%BSA (Cappel) and then ABTS substrate. The isotype of the anti-DNA antibodies was analyzed by using peroxidase or alkaline phosphatase conjugated antibodies to IgM (Southern Biotechnology Associates, Birmingham, Alabama, USA), IgG1 (Accurate Antibodies), IgG2a (Accurate Antibodies), IgG2b (Southern Biotechnology Associates) or IgG3 (Southern Biotechnology Associates). 
ELISpot assay. Separate groups of mice were used for some of these experiments. Mice were treated with highdose Ad-CTLA4Ig or with control mouse IgG2a, and spleens were harvested 8 days, 21 days, and 12-30 weeks after treatment. Three to five mice were examined in each group. Threefold serial dilutions of spleen or bone marrow cells were plated overnight on DNA-coated plates starting at $3 \times 10^{6}$ cells per well. After washing, the plates were incubated with biotin conjugated antiIgM or anti-IgG (Southern Biotechnology Associates) $1 / 1000$ in PBS/1\% BSA for 2 hours, followed by streptavidin alkaline phosphatase (Southern Biotechnology Associates) $1 / 1000$ in PBS/1\% BSA for 45 minutes. Plates were then developed with BCIP (Sigma Chemical Co.) $1 \mathrm{mg} / \mathrm{mL}$ in AMP buffer $(0.75 \mathrm{mM} \mathrm{MgCl} / 0.01 \%$ Triton-X/9.58\% 2-amino-methyl-1propanol [pH 10.25]). Spots were counted using a dissecting microscope. Total numbers of immunoglobulin-secreting cells were measured the same way using anti-mouse immunoglobulins to coat the plates.

Generation of bybridomas. Hybridomas were generated from spleen cells by standard techniques using NSO and/or NSO-bcl 2 cells (17) as fusion partner. Hybridomas were screened for anti-DNA activity by ELISA as already described here, and positive wells were cloned by limiting dilution. Stable clones were then analyzed for immunoglobulin isotype by ELISA. For measurement of apparent affinity, the concentration that yielded $80 \%$ of maximal binding to a DNA plate was determined. This amount of supernatant was then preincubated with increasing concentrations of double stranded salmon sperm DNA ranging from $0.1 \mu \mathrm{g} / \mathrm{mL}$ to 1 $\mathrm{mg} / \mathrm{mL}$ before testing by ELISA. Apparent affinity was then calculated as described by Nieto et al. (18). The heavy and light chain genes of stable hybridomas were isolated by RT-PCR using a high-fidelity polymerase (Vent polymerase; New England Biolabs Inc., Beverly, Massachusetts, USA), a mix of VH and VL FR1 5' primers and constant region IgM, IgG or Ck $3^{\prime}$ primers (19). PCR products were directly sequenced in the AECOM sequencing facility. Sequences were analyzed by BLAST search (http://www.ncbi.nlm.nih.gov/blast/) and were aligned according to Kabat numbering using IMGT, the international ImMunoGeneTics database (http://www.imgt.cnusc.fr).

Analysis of class switching. Evidence of active class switching was sought by semiquantitative RT-PCR analysis of I $\gamma$-C $\gamma$ transcripts from 30-36 week spleens. cDNA was generated using random primers, normalized for $\mathrm{CDNA}$ content using actin primers, and subjected to PCR using primers for the $\mathrm{I} \gamma 2 \mathrm{~b}$ and $\mathrm{C} \gamma 2 \mathrm{~b}$ exons as described previously (20) and for the I $\gamma 1$ (5'GACGGCTGCTTTCACAGCTT3') and C $\gamma 1$ (5'AgTTTGGGAGCAGATCCAGG3') exons. PCR products were also analyzed by Southern blot using I $\gamma 2 \mathrm{~b}-\mathrm{C} \gamma 2 \mathrm{~b}$ or $\mathrm{I} \gamma 1-\mathrm{C} \gamma 1 \mathrm{P}^{32}$ labeled cDNA probes.

Analysis of the $V_{H} B W-16$ gene. To understand further the molecular basis for the CTLA4Ig-induced decrease in frequency of B cells producing anti-dsDNA antibodies of the IgG isotype, we performed a detailed analysis of the $\mathrm{V}_{\mathrm{H}} \mathrm{BW}-16$ gene. This gene is strongly associated with anti-dsDNA antibody activity and with glomerular binding activity in both NZB/NZWF1 and MRL/lpr mice (21). Although present in the germline of several normal strains, $\mathrm{V}_{\mathrm{H}} \mathrm{BW}-16$ is not expressed in these strains unless they are experimentally induced to mount an antidsDNA antibody response (22). In such cases, the autoantibodies are either all of the IgM isotype, or are of low affinity, indicating that antibodies using this gene are regulated in the peripheral B-cell compartment of normal mice. Separate IgM and IgG cDNA libraries were constructed by RT-PCR as described previously $(22,23)$ from the spleens of nine CTLA4Ig-treated and six control 30- to 52-week mice, two 22-week NZB/NZW F1 mice, and two BALB/c controls. Two hundred to four hundred colonies from each library were hybridized at $54^{\circ} \mathrm{C}$ with $2 \mathrm{~V}_{\mathrm{H}} \mathrm{BW}-16$-specific oligomers (CDR1: 5'CTGCTGCAAGGCTTCTGGTT3': CDR2: 5'GGAATTAATCCTTACTATGGT3'). The quality of each library was confirmed by stripping and rehybridizing each filter with the IgM or IgG constant region oligomers. Positive colonies were picked, and inserts from purified plasmids were sequenced in the AECOM sequencing facility.

All positive colonies contained J558 genes, and 80-90\% used the $\mathrm{V}_{\mathrm{H}} \mathrm{BW}-16$ gene, showing that the screening procedure is satisfactory. To ensure that all positive colonies had been identified, 500 CDR1/CDR2negative colonies from control mice were screened with a FR3 $\mathrm{V}_{\mathrm{H}} \mathrm{BW}-16$ primer (5'ATAGACTGCAGAGTCCTCAG3'). 100 positive colonies were then screened with a $3^{\prime} \mathrm{V}_{\mathrm{H}} \mathrm{BW}$-16-specific CDR2-FR3 oligonucleotide (5'CCATAGTAAGGATTAATATTTCC3'). Of eight weak positive colonies identified, only one used the $\mathrm{V}_{\mathrm{H}} \mathrm{BW}-16$ gene, showing that the screening procedure has a false negative rate of only $1 \%$.

Sequences were compared with the germline $\mathrm{V}_{\mathrm{H}} \mathrm{BW}$ 16 sequence using BLAST search. Mutations were analyzed in the $V$ region only, and the last four nucleotides of the $\mathrm{V}$ region were excluded from the mutation analysis, as there were many differences in these nucleotides owing to junctional diversity. Replacement/silent mutation ratios were calculated, and the frequency of mutations at the RGYW hot spot on both strands and the trinucleotide hot spots AGY, GCT, GTA, TAC, ATT, and AAT in all reading frames were determined (24). Mutations shared by more than one clonally related sequence were analyzed only once. Comparisons of percentage of hot spot mutations in treated versus untreated mice were performed using the $\chi^{2}$ test. Finally, the number of transitions and transversions was determined and compared with the expected number of randomly generated mutations based on the frequency of each nucleotide in the $\mathrm{V}_{\mathrm{H}} \mathrm{BW}-16$ sequence.

Statistical analysis. Proteinuria and survival data were analyzed using Kaplan Meier curves and log rank test. Comparisons shown in Figures 1, 3, 4, 6, 7 and 8 were performed using Wilcoxon rank sum test. Comparisons 


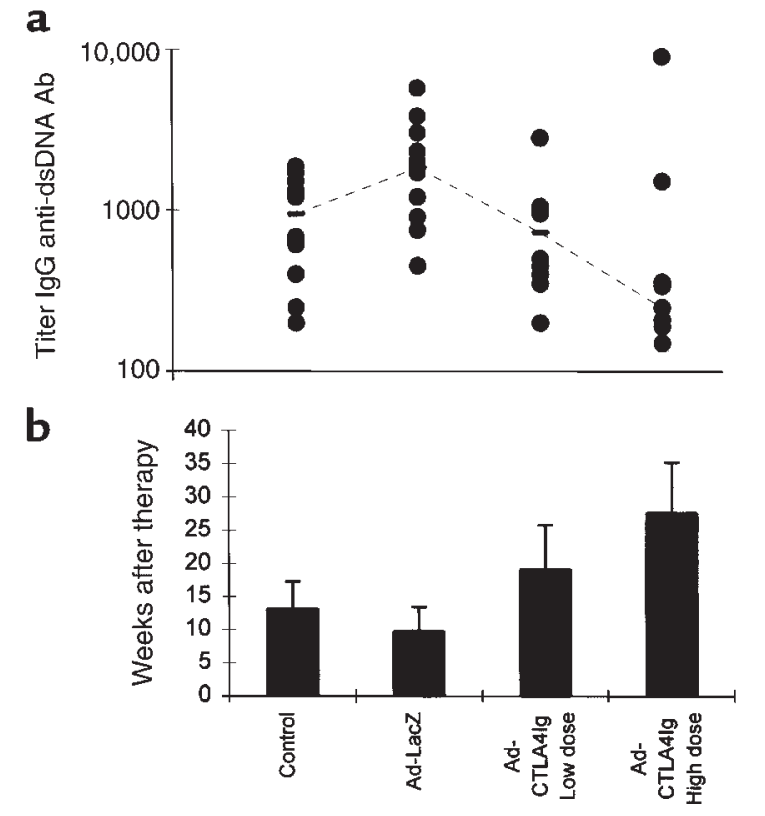

Figure 1

(a) Maximum anti-dsDNA titers reached after Ad-CTLA4Ig injection. Titers for mice in the high-dose group whose titers diminished over time were measured at 52 weeks (high dose versus control, $P=0.04$ ). (b) Mean number of weeks (+1 SD) after treatment at which maximum anti-dsDNA titers were reached (low dose versus control, $P=0.03$; high dose versus control, $P=0.0006)$.

shown in Tables 1 and 3 were performed using $\chi^{2}$ analysis or Fisher's exact test. Only significant $P$ values are shown.

\section{Results}

Serial CTLA4Ig levels. Ten mice were injected with lowdose Ad-CTLA4Ig $\left(5 \times 10^{8} \mathrm{pfu}\right)$ and ten mice were injected with the high dose $\left(2 \times 10^{9} \mathrm{pfu}\right)$. CTLA4Ig was detected in the serum within 12 hours of injection, and peak levels of were achieved at 7-9 days. In mice receiving low-dose Ad-CTLA4Ig, serum levels of CTLA4Ig peaked at $219 \pm 153 \mu \mathrm{g} / \mathrm{mL}$ and were detected for only 40-150 days, whereas in the high-dose Ad-CTLA4Ig group, levels of CTLA4Ig peaked at 3,317 $\pm 1,608$ $\mu \mathrm{g} / \mathrm{mL}$ and were sustained for up to 250 days.

Antiadenoviral antibodies. IgG anti-adenoviral antibodies measured by ELISA were present in high titer at 21 days in the sera of the mice receiving the low-dose AdCTLA4Ig, but were not detected in the high-dose group. Neutralizing antiadenoviral titers were markedly reduced in both low- and high-dose groups compared with mice that received the irrelevant Ad-LacZ virus. Thus, despite expansion of an antiadenoviral IgG response in the lowdose group, full maturation of the protective neutralizing response did not occur (data not shown). We have obtained similar results in non-autoimmune mice (B. Reddy et al., manuscript submitted for publication).

Development of anti-DNA antibodies, proteinuria, and survival. Anti-DNA antibody titers in the control groups increased over time, reaching maximal levels at 32-35 weeks; most of these mice died by 52 weeks of age (Fig- ure 1). The mice treated with irrelevant adenovirus developed higher titers of anti-DNA antibodies, reaching peak levels approximately 4 weeks earlier than the controls, and they developed proteinuria and died earlier than the controls (Figure 2). These differences were not statistically significant and may be related to the release of inflammatory mediators during the course of an adenoviral infection. The mice that received lowdose Ad-CTLA4Ig had a statistically significant delay in the time to reach peak levels of anti-DNA antibodies $(P=0.03)$, and a 6 - to 8 -week delay in the onset of proteinuria and death, which was not, however, significantly different from the Ad-LacZ-treated mice or from the IgG2a or untreated controls (Figure 2). In contrast, the mice that were injected with high-dose AdCTLA4Ig were all alive at 52 weeks of age $(P=0.0002$ compared with untreated or IgG2a controls); only one of these mice had developed proteinuria at this point $(P=0.0001)$ and serum anti-DNA levels had risen from baseline in only two $(P=0.04)$. Disease did begin to develop in some of the mice in this group after the age of 52 weeks (data not shown).

Histological examination of the kidneys. Kidneys were examined from control NZB/NZW F1 nephritic mice aged 36-52 weeks and from high-dose AdCTLA4Ig-treated mice sacrificed at 36,52, and 60 weeks. Control mice had severe glomerulonephritis with membrano-proliferative disease and sclerosis of glomeruli, tubular casts, and mononuclear cell infiltration around blood vessels and in the calyceal areas. Glomerular disease in the treated mice was very mild, tubular casts were rarely seen and calyceal mononuclear cell infiltration was absent. Deposition of IgG and complement in the glomeruli was markedly diminished in the treated mice compared with controls (Figure 3).

FACS ${ }^{\circledR}$ analysis. Spleen cells from six 30- to 46-week AdCTLA4Ig-treated (three high dose and three low dose) and six age-matched (two untreated, two IgG2a treated, and two Ad-LacZ treated) nephritic control mice were analyzed by $\mathrm{FACS}^{\circledR}$ for expression of B- and T-cell markers. Two 22-week NZB/NZW F1 mice and $2 \mathrm{BALB} / \mathrm{c}$ mice were examined as negative controls. The total number of spleen cells was increased in the control mice compared with either the young or the treated mice $\left(1.9 \pm 0.5 \times 10^{8}\right.$ in controls vs. $0.95 \pm 0.4 \times 10^{8}$ in treated mice; $P=0.03$, and $0.90 \pm 0.1 \times 10^{8}$ in young mice). Untreated NZB/NZW F1 mice had the same proportions of $B$ and $\mathrm{T}$ cells as normal BALB/c controls. This was not altered by CTLA4Ig treatment. Young NZB/NZW F1 mice had normal numbers of CD8 cells; however, older nephritic mice displayed a loss of CD8 cells with a markedly increased $\mathrm{CD} 4 / \mathrm{CD} 8$ ratio. In contrast, the treated mice had a normal CD4/CD8 ratio. Young NZB/NZW F1 mice showed evidence of CD4 $\mathrm{T}$ cell activation as demonstrated by expression of the early activation marker CD69. Even higher numbers of activated CD4 cells were observed in the older NZB/NZW F1 mice. In contrast, Ad-CTLA4Ig-treated mice had levels of CD69 expression comparable with the BALB/c controls (Figure 4). There 
a

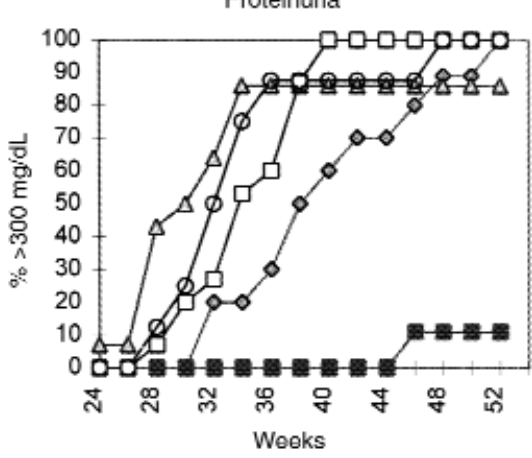

b

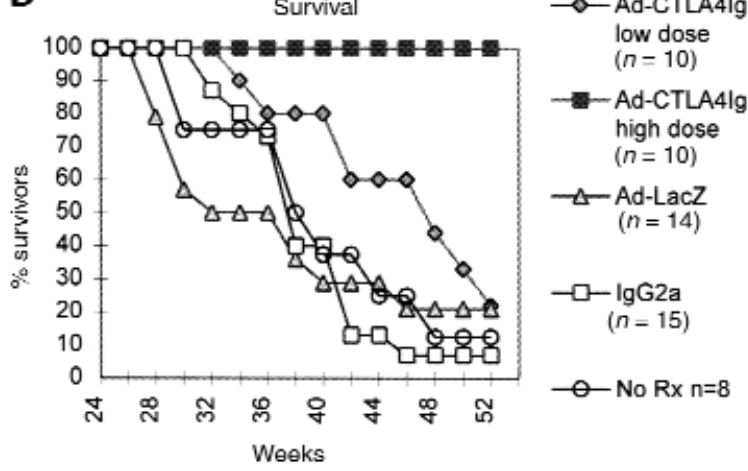

Figure 2

Cumulative percentage of mice in each group that developed fixed proteinuria (a) or died (b) at each time point. One mouse in each of the low- and high-dose groups died of a surgical complication at the age of 47 and 36 weeks, respectively, and was removed from the analysis. a: High-dose versus IgG2a or untreated control, $P=0.0001$; $\mathbf{b}$ : high-dose versus IgG2a or untreated control, $P=0.0002$.

was no difference between the two groups of treated mice. Despite this finding, transition of CD4 $\mathrm{T}$ cells from the naive to the memory compartment as assessed by the phenotypic markers CD44 and CD62L (25) was not inhibited by CTLA4Ig. Young NZB/NZW F1 mice had similar numbers of naive (CD44lo/CD62L hi) and memory $\left(\mathrm{CD} 44^{\mathrm{hi}} / \mathrm{CD} 62 \mathrm{~L}^{\mathrm{lo}}\right) \mathrm{CD} 4$ cells as $\mathrm{BALB} / \mathrm{c}$ mice. However, in older nephritic mice, more than $80 \%$ of the CD4 T cells had a memory phenotype and less than $5 \%$ of the cells had a naive phenotype. This phenotypic pattern was also observed in the Ad-CTLA4Ig-treated mice (Figure 4).

$B$-cell production of total immunoglobulins and anti-DNA antibodies. To determine whether CTLA4Ig treatment altered the polyclonal expansion of IgM-producing cells, total serum IgM was measured at age 38 and 52 weeks. Serum IgM levels in the NZB/NZW F1 mice were tenfold higher than in $\mathrm{BALB} / \mathrm{c}$ mice $(P<0.05)$, and this was not altered by either low-dose or high-dose Ad-CTLA4Ig. Total serum IgG levels were also unaffected up to 30 weeks after treatment, as were $\operatorname{IgG}$ isotypes (data not shown).

To enumerate total numbers of immunoglobulinsecreting and anti-dsDNA antibody-producing B cells in the treated mice and follow their kinetics, total immunoglobulin and anti-dsDNA ELISpots were performed on spleen and/or bone marrow samples from Ad-CTLA4Ig-treated and control NZB/NZW F1 mice at various times after treatment (Figure 5). The frequency of IgM anti-DNA-secreting B cells in the spleens was increased in young NZB/NZW F1 mice compared with nonautoimmune mice. Neither the total number of IgM-secreting B cells nor the frequency of IgM anti-DNA antibody-secreting B cells decreased after treatment with Ad-CTLA4Ig. However, as the untreated NZB/NZW F1 mice aged, there was a five- to tenfold increase in the number of IgM antiDNA antibody-producing B cells. This increase was not observed in the treated mice, suggesting that agerelated activation and proliferation of these cells had been blocked by CTLA4Ig.

There was no difference in the frequency of IgG-secreting or IgG anti-DNA antibody-secreting spleen cells between Ad-CTLA4Ig-treated mice and NZB/NZW F1 controls 8 days after treatment, and the spleens from both groups of mice were enlarged. By 3 weeks after $\times 400$
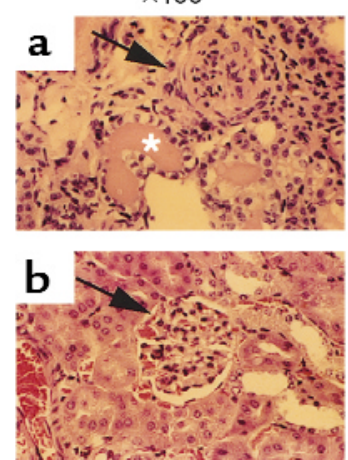

$\times 100$
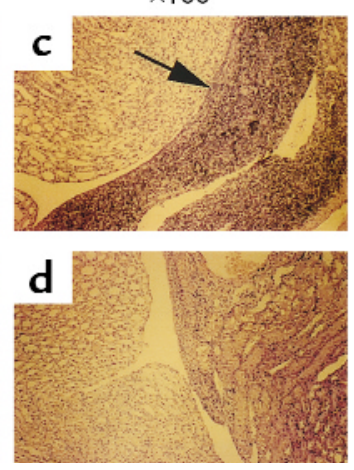
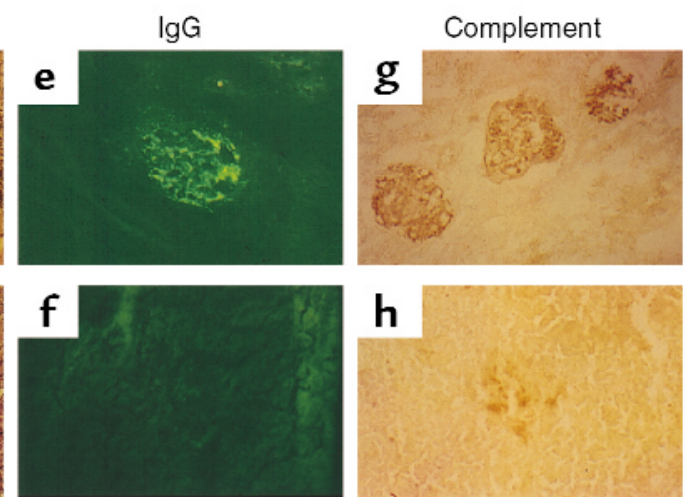

Figure 3

Renal histology from treated $(\mathbf{b}, \mathbf{d}, \mathbf{f}$, and $\mathbf{h})$ compared with control (a, $\mathbf{c}, \mathbf{e}$, and $\mathbf{g}$ ) mice. Treated mice have more normal glomeruli (arrows in $\mathbf{a}$ and $\mathbf{b}$ ) and absence of tubular casts $\left({ }^{*}\right)$. Lymphocyte infiltration in the calyceal regions (arrow in $\left.\mathbf{c}\right)$ is absent (d) and glomerular deposition of $\operatorname{lgG}(\mathbf{f})$ and complement $(\mathbf{h})$ are diminished. One representative mouse from each group is shown. 
Table 1

Frequency and isotype of DNA-binding hybridomas from CTLA4Ig-treated and control NZB/NZW F1 mice

\begin{tabular}{|c|c|c|c|c|c|c|}
\hline \multirow[b]{2}{*}{ Mouse } & \multirow{2}{*}{\multicolumn{2}{|c|}{$\begin{array}{c}\text { Titer IgG } \\
\text { Anti-DNA Ab }\end{array}$}} & \multirow{2}{*}{$\begin{array}{c}\text { Fusion partner } \\
\qquad \mathrm{NSO}^{\mathrm{A}}\end{array}$} & \multirow[b]{2}{*}{ NSO-bcl- $2^{A}$} & \multicolumn{2}{|c|}{ Isotype } \\
\hline & & & & & $\lg ^{B}$ & $\lg G^{B}$ \\
\hline Control & $22 w$ & $<1 / 50$ & $2 / 106$ & ND & 1 & 1 \\
\hline Control & $22 w$ & $1 / 50$ & $1 / 121$ & ND & 1 & 0 \\
\hline Control & $24 w$ & $<1 / 50$ & $4 / 228$ & ND & 4 & 0 \\
\hline Control & $33 w$ & $1 / 500$ & $39 / 449$ & ND & $3 / 12$ & $9 / 12$ \\
\hline Control & $35 w$ & $1 / 1,000$ & $48 / 528$ & ND & $1 / 8$ & $7 / 8$ \\
\hline Control & $52 w$ & $1 / 1,000$ & $92 / 282$ & ND & $17^{c}$ & $75^{c}$ \\
\hline Ad-CTLA4Ig low & $30 w$ & $1 / 50$ & $0 / 168$ & $2 / 352$ & 2 & 0 \\
\hline Ad-CTLA4Ig high & $31 w$ & $1 / 100$ & $5 / 275$ & $1 / 392$ & $3 / 4$ & $1 / 4$ \\
\hline Ad-CTLA4Ig high & $35 w$ & $<1 / 50$ & $0 / 23$ & $0 / 65$ & - & - \\
\hline Ad-CTLA4Ig high & $46 w$ & $1 / 100$ & $3 / 173$ & $1 / 71$ & $0 / 2$ & $2 / 2$ \\
\hline Ad-CTLA4Ig high & $1 w$ & $1 / 75$ & $7 / 177$ & $2 / 43$ & 9 & 0 \\
\hline
\end{tabular}

${ }^{A}$ Frequency of anti-DNA antibody-producing hybridomas/total number screened. $P$ values: $>30$-week control versus young control or treated, $P<0.0001$ ( $\chi^{2}$ test) ${ }^{\mathrm{B}} P$ values for IgM/lgG ratios: $>30$-week control versus young control, $P=0.0005$; $>30$-week control vs. treated, $P<0.0001$ (Fisher's exact test). ${ }^{\circ}$ Uncloned lines.

treatment, however, spleens from the treated mice were no longer enlarged and there was a $90 \%$ reduction in the number of IgG-secreting cells. In high-dose AdCTLA4Ig-treated mice examined more than 10 weeks after treatment, the frequency of IgG anti-dsDNA antibody-secreting $\mathrm{B}$ cells was 100 -fold less than in agematched controls $(P=0.02)$. This effect was only partially accounted for by the reduction in overall numbers of IgG-secreting cells in the spleens. Bone marrows from 52-week-old treated mice displayed a similar reduction in IgG anti-dsDNA antibody-producing B cells $(P=$ 0.03 ), but the total number of IgG-producing B cells was no different from that of aged controls.

Generation of bybridomas. Spleen cell fusions were performed at intervals after treatment to determine whether high-affinity anti-DNA producing B cells had been anergized. Hybridomas were generated with the standard NSO fusion partner and/or with a bcl-2 transfected NSO line (NSO-bcl-2) that allows generation of hybridomas from anergic $\mathrm{B}$ cells that would otherwise be destined for apop- tosis (17). The frequency of DNA-binding hybridomas from each fusion is shown in Table 1. Far fewer DNA-binding hybridomas were recovered from Ad-CTLA4Ig-treated mice than from controls treated with IgG2a or Ad-LacZ $(P<0.0001)$, and there was no rescue of autoreactive hybridomas using the bcl-2 transfected fusion partner, indicating that anergy is not a major mechanism for the observed results. Similar results were obtained when splenic B cells were stimulated for 4 days with LPS. IgG anti-DNA antibodies were detected in the LPS culture supernatants from untreated NZB/NZW F1 mice 30 weeks and more, but not in the supernatants from 22week NZB/NZW F1 mice or 30-week Ad-CTLA4Ig-treated mice (data not shown), again suggesting that anergic anti-DNA antibody-producing B cells were not present.

Characterization of bybridoma antibodies. Twenty strongly positive DNA-binding hybridomas from the control mice and all the positive hybridomas from the treated mice were cloned, and antibody isotypes of stable lines were determined by ELISA. Sixteen of 20 hybridomas from the
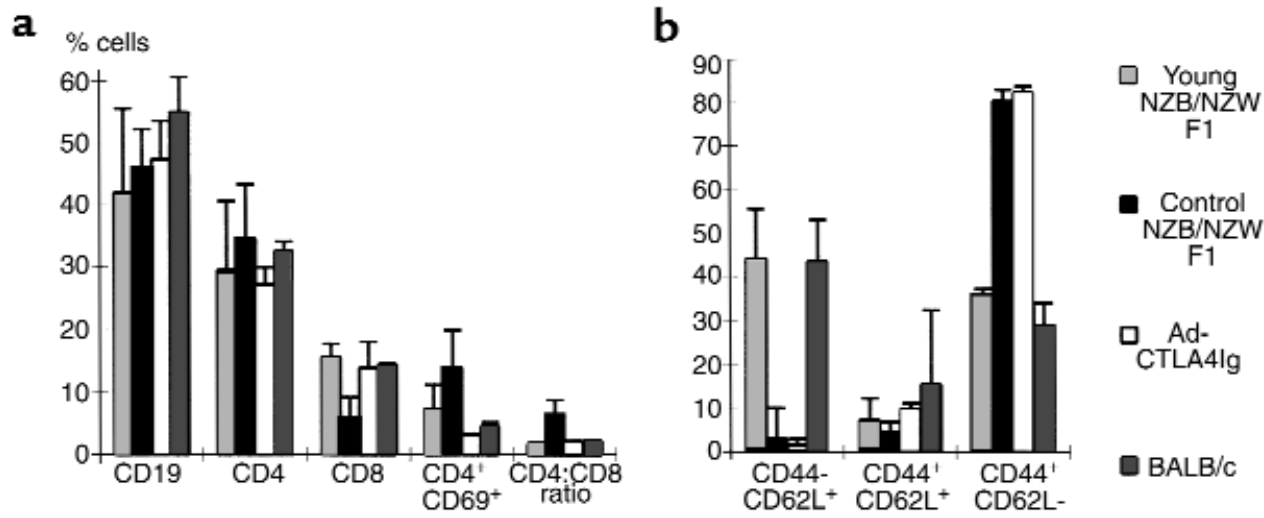

\section{Figure 4}

(a) Mean percent of CD4-positive, CD8-positive, CD19-positive, and CD4/CD69-positive cells (+1 SD) in spleens from six treated and six control NZB/NZW F1 mice age 30-46 weeks, two young NZB/NZW F1 mice, and two BALB/c mice. CD19 and CD4 counts were no different between treated mice and controls. Percent CD8 cells was higher $(P=0.005), \mathrm{CD} 4 / \mathrm{CD} 8$ ratio was lower $(P=0.006)$, and percent CD4/CD69 cells was lower $(P=0.014)$ in treated mice versus age-matched controls. (b) Mean percent of naive $\left(C D 44\right.$ lo $\left./ C D 62 L^{\text {hi }}\right)$ and memory (CD44hi/CD62 L $\left.{ }^{\text {lo }}\right)$ CD4 T cells. There was no difference between Ad-CTLA4lg-treated mice and age-matched controls. CD44hi/CD62 Li cells are in transition from the naive to memory compartment, but this subset was not prominent in any of the groups. 
Table 2

Characteristics of IgG DNA-binding antibodies derived from hybridomas from Ad-CTLA4Ig-treated mice compared with those from control mice

\begin{tabular}{|c|c|c|c|c|c|}
\hline Cell line & Treatment & Fusion & Isotype & Anti-DNA ${ }^{A}$ & $\begin{array}{c}\text { Apparent affinity } \\
\text { for dsDNA }\end{array}$ \\
\hline 156 & Ad-LacZ & NSO & $\operatorname{lgG} 2 b$ & 1.350 & $4.1 \times 10^{-8}$ \\
\hline 78 & $\lg G 2 a$ & NSO & $\lg G 2 b$ & 1.680 & $1.0 \times 10^{-9}$ \\
\hline 174 & Ad-CTLA4Ig high & NSO-bcl2 & $\lg G 2 b$ & 0.840 & $1.2 \times 10^{-7}$ \\
\hline 43 & $\lg G 2 a$ & NSO & $\lg G 2 a$ & 1.701 & $3.0 \times 10^{-9}$ \\
\hline 31 & $\lg G 2 a$ & NSO & $\lg G 2 a$ & 1.082 & $4.6 \times 10^{-9}$ \\
\hline 6 & Ad-CTLA4Ig high & NSO-bcl2 & $\lg G 2 a$ & 0.595 & $1.1 \times 10^{-6}$ \\
\hline 33 & Ad-CTLA4Ig high & NSO & $\operatorname{lgG} 2 a$ & $0.116^{\mathrm{B}}$ & ND \\
\hline
\end{tabular}

${ }^{A}$ Expressed as OD units using an ELISA performed at the concentration of supernatant that achieved maximal binding to an anti-IgG-coated plate. ${ }^{B}$ Weak positive DNA binding observed at twofold higher concentrations.

control mice produced antibodies that were of the IgG isotype, whereas only three of 17 hybridomas from the treated mice produced IgG anti-DNA antibodies $(P=$ 0.0001). Isotype analysis of these three hybridomas revealed that two were of the IgG2a isotype and one of the IgG2b isotype. The DNA-binding hybridomas from the untreated NZB/NZW F1 mice were then screened for isotype, and two hybridomas of the IgG2a isotype and two of the $\operatorname{IgG} 2 \mathrm{~b}$ isotype were randomly chosen for use as controls in subsequent studies. Hybridoma supernatants normalized for IgG content by ELISA were tested for DNA reactivity, apparent affinity for DNA and for binding to glomeruli in vitro. The apparent affinities for DNA of the control hybridomas ranged from $4.1 \times 10^{-8}$ to $3 \times$ $10^{-9}$, whereas those of the hybridomas from treated mice were 1-2 logs lower (Table 2). Three of the 4 control hybridoma anti-DNA antibodies bound to glomeruli in vitro (26), but none of the 3 hybridoma antibodies from treated mice did (data not shown). Thus, the IgG antiDNA antibodies from hybridomas generated from treated mice are of the same isotypes as those from control mice but are likely to be less pathogenic.
Sequencing of immunoglobulin genes from the bybridomas. To analyze the $\mathrm{V}$ region usage of the anti-DNA antibody-producing hybridomas obtained from the treated mice, the immunoglobulin heavy and light chain genes of all three IgG antiDNA antibodies and seven of $14 \mathrm{IgM}$ anti-DNA antibodies were sequenced. Three of the four IgM antibodies derived independently from one high-dose-treated mouse were identical, suggesting that this mouse had an oligoclonal IgM expansion. Comparison of the heavy chain sequences with the most homologous gene found by BLAST analysis indicated that the hybridomas used a variety of heavy chain $\mathrm{V}, \mathrm{D}$, and $\mathrm{J}$ genes. In all cases, the most homologous heavy chain gene identified by BLAST search was derived from a murine antiDNA antibody, suggesting that the heavy chain gene repertoire used in the treated mice was not unusual. A variety of light chain $\mathrm{V}$ region genes was also used. The light chain J regions used were either Jk1 or Jk2, suggesting that light chain receptor editing was not a major mechanism for regulation of these antibodies. These sequences have been submitted to Genbank and are available under accession numbers AF 276278-gl Analysis of class switching. To determine whether the observed decrease in the frequency of IgG-secreting B cells in the spleens of treated mice was due to a block in class switching, we performed semiquantitative PCR on spleen RNA to detect the presence of sterile I-C transcripts. Sterile transcripts for IgG1 were detected in all four control mice tested but in only one of the treated mice (Figure 6). Sterile transcripts for IgG2b were detected on agarose gels in all four control mice tested but in none of the treated mice. To confirm these results, Southern blotting was performed on the PCR products, and only one of five of the treated mice had a

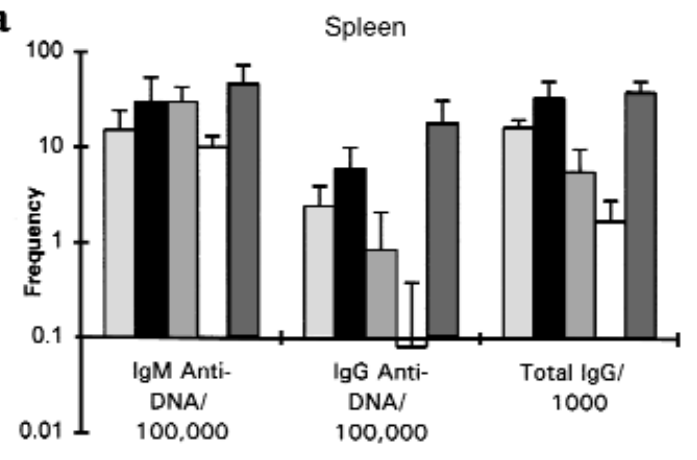

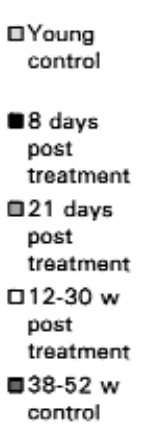

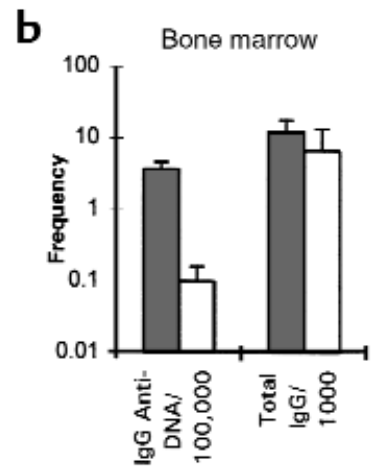

\section{Figure 5}

ELISpot assays (mean + 1 SD) for frequency of anti-DNA antibody-producing B cells and IgG-producing B cells in the spleens (a) and bone marrows $(\mathbf{b})$ of treated and age-matched control mice at intervals after treatment. At least three mice were examined in each group. All the spleens from treated mice were harvested from high-dose-treated mice that did not have an increase in serum anti-DNA levels or any evidence of kidney disease. All the control mice had anti-DNA antibodies. Significant $P$ values: spleen anti-DNA IgG: treated versus young or old control, $P<0.02$; spleen total IgG: treated versus young control, $P=0.04$; treated versus old control, $P=0.02$; bone marrow anti-DNA IgG: treated versus control, $P=0.03$. 


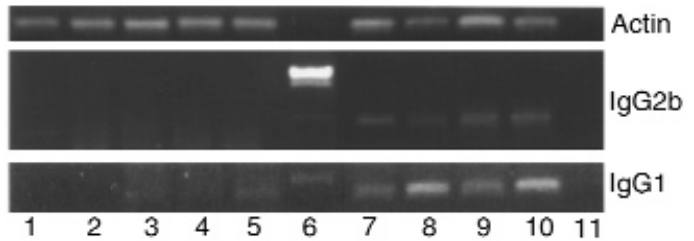

Figure 6

RT-PCR of spleen mRNA for IgG1 and IgG2a sterile transcripts. Lanes 1-3, Low dose Ad-CTLA4Ig; lanes 4, 5, High dose Ad-CTLA4Ig; lane 6 , marker is loaded in the IgG2b and IgG1 panels. In the IgG1 panel, only the $600 \mathrm{bp}$ marker is shown. Lanes $7-10$, age matched control mice; lane 11, negative control.

detectable sterile transcripts for both IgG1 and IgG2b (data not shown). Thus, CTLA4Ig induces a substantial block in class switching.

Analysis of the VHBW-16 gene. To analyze the effect of CTLA4Ig on usage, isotype switching and somatic mutation of the autoreactive $\mathrm{V}_{\mathrm{H}} \mathrm{BW}-16$ gene, J558 specific IgM and IgG cDNA libraries were constructed by RT-PCR from spleens of nine CTLA4Ig treated (three low dose and six high dose) and six untreated mice ranging from 30 to 52 weeks of age. These mice included all the mice from which hybridomas were generated. The spleens of two $\mathrm{BALB} / \mathrm{c}$ mice were used as negative controls. As expected, no positive clones were obtained from either the IgM or IgG BALB/c libraries. $\mathrm{V}_{\mathrm{H}} \mathrm{BW}-16$ was detected in both $\operatorname{IgM}$ and $\operatorname{IgG} \mathrm{cDNA}$ libraries from eight of nine treated mice and from all the control NZB/NZWF1 mice.

IgM sequences. Only nine IgM sequences were obtained from five 30- to 52-week NZB/NZW F1 control libraries. These were all germline encoded and clonally unrelated. Eighteen clonally unrelated sequences were obtained from the IgM libraries of seven treated mice, showing that CTLA4Ig treatment does not alter the abnormal expansion of immature cells that utilize $\mathrm{V}_{\mathrm{H}} \mathrm{BW}-16$ in NZB/NZWF1 mice. Seven of these sequences contained somatic mutations, indicating that somatic mutation can occur despite the block in class switching. However, the replacement/silent ratio of mutations in the CDR and FR regions was not suggestive of antigen selection (Table 3).

IgG sequences from control mice. Seventeen IgG sequences were obtained from two 22-week NZB/NZW F1 mice. Five of ten sequences from one of these mice and two of seven from the other mouse were clonally related. Few mutations were observed in these sequences, most having only a single mutation. Sequencing of $30 \mathrm{~V}_{\mathrm{H}} \mathrm{BW}-16$ genes from the IgG cDNA libraries of older 30- to 52-week control mice revealed that three of the six mice had clonally related sequences and nearly all the sequences had somat- ic mutations, particularly in CDR2. Analysis of the replacement/silent ratio of mutations in the CDR and FR regions now showed an increase in the number of replacement mutations in CDR compared with FR regions, suggestive of antigen selection (Table 3 ).

IgG sequences after treatment. Thirty-two IgG $\mathrm{V}_{\mathrm{H}} \mathrm{BW}-16$ sequences were obtained from libraries from nine treated mice. In three of these mice, only one positive sequence was recovered from 400 screened colonies, and in one mouse, no positive colonies were obtained. Clonally related sequences were retrieved from four of the five mice from which multiple clones were recovered. Analysis of somatic mutations revealed differences in the mutation frequency and patterns between the treated and control mice. A pooled mutation analysis from all the sequences is shown in Figure 7. There was a $53.1 \%$ reduction in the frequency of somatic mutation in the treated mice compared with the old controls $(P<0.0001)$, but there were more somatic mutations observed in the treated mice than in the young controls $(P=0.05)$. In addition, there were many more replacement than silent mutations observed in the FR regions of treated mice than in either young or old controls $(P<0.002)$ (Table 3$)$.

Subtle differences between Ad-CTLA4Ig-treated and control mice were observed in the CDR2 region. In control 30- to 52-week mice, mutations occurred throughout this region, but in the treated mice, the mutations were restricted to positions 57-61 of CDR2. The two most common mutations observed in the treated mice were serine $\rightarrow$ asparagine at positions 58 and 60 . In contrast, mutations to arginine or lysine were frequently observed in the CDR2 regions of clones from control mice (Figure 8).

Because it has been previously suggested that the presence of basic amino acids in the $\mathrm{V}_{\mathrm{H}} \mathrm{BW}-16 \mathrm{CDR} 3$ region contributes to DNA binding $(22,27)$, we analyzed the CDR3 regions of all the $V_{H} B W-16$ clones for the presence of Arg or Lys residues. Basic residues in the CDR3 region were found in clones from both the IgM and IgG libraries, and there was no difference between AdCTLA4Ig-treated and control mice (data not shown).

Analysis of the pattern of somatic mutation. A total of 108 independent mutations from the IgG sequences from control mice and 54 mutations from the IgG sequences from treated mice were analyzed. In both control and treated mice, the frequency of mutations of $G$ residues,
Table 3

Mutation analysis of $\mathrm{V}_{\mathrm{H}} \mathrm{BW}-16$ genes from Ad-CTLA4lg-treated and control NZB/NZW F1 mice

\begin{tabular}{lccccc}
\hline Group & Library & No. sequences & No. mutations & \multicolumn{2}{c}{ Replacement/silent ratio } \\
isotype & analyzed & & \multicolumn{2}{c}{ CDR } & Framework \\
Control & IgM & 9 & 0 & $10: 8$ & $4: 3$ \\
Treated & IgM & 18 & 25 & $43: 12$ & $31: 22$ \\
Control & IgG & 30 & $108(P<0.0001)^{\mathrm{A}}$ & $19: 4$ & $26: 5(P<0.002)^{\mathrm{C}}$ \\
Treated & IgG & 32 & $54(P=0.05)^{\mathrm{B}}$ & $4: 2$ & $7: 4$ \\
$22 W$ & IgG & 16 & 17 & &
\end{tabular}

ACompared with treated. ${ }^{\mathrm{B} C}$ Compared with 22-week control. ${ }^{\mathrm{C} C o m p a r e d}$ with age-matched control. 


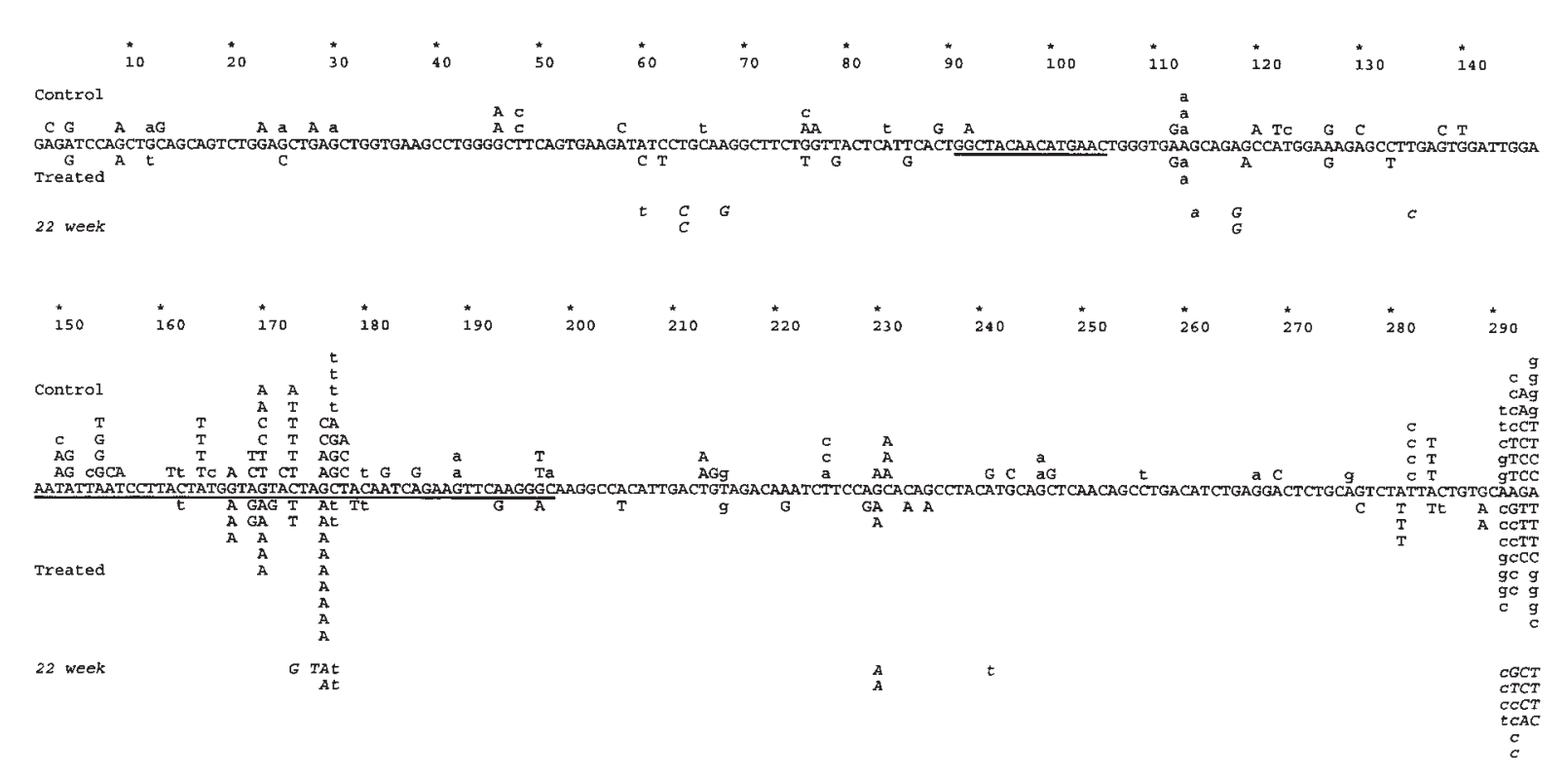

\section{Figure 7}

Pooled mutation analysis of all the clones obtained from the IgG $V_{H} B W-16$ cDNA libraries compared with the germline gene. Sequences from controls are shown above the germline sequence. Sequences from treated mice are shown below the germline sequence. Sequences from young controls are shown in italics. Replacement mutations are in upper case, and silent mutations in lower case. Mutations observed in clonally related sequences are shown only once. Analysis of these dataexcluding gene pairs 291-4 is shown in Table 3.

particularly $\mathrm{G} \rightarrow \mathrm{A}$ transitions, was greater than expected $(P<0.001)$, whereas the frequency of $\mathrm{T}$ mutations was less than expected $(P=0.06$ for controls and $P=0.007$ for CTLA4Ig-treated mice). The ratio of transitions to transversions was increased in the treated mice (39:15 vs. $62: 46$ in controls; $P<0.03)$. Increased targeting of mutations to both triplet and RGYW hot spots was evident in the sequences from control and treated mice, with no difference between the two groups (data not shown).

\section{Discussion}

The NZB/NZW F1 spontaneous murine model of SLE is characterized by both polyclonal activation of naive $B$ cells and excessive activation of $T$ cells that occur early in life. Disease onset occurs at the age of 4-6 months when autoreactive $B$ cells become further activated and their immunoglobulin genes undergo class switching and somatic mutation to produce high-affinity pathogenic autoantibodies (28-32). This process is dependent on costimulation via $\mathrm{B} 7 / \mathrm{CD} 28$ (8).

We have engineered a nonreplicating adenovirus that expresses high levels of murine CTLA4Ig, allowing us to achieve long-term blockade of the B7/CD28 pathway in NZB/NZW F1 mice after a single intravenous injection of virus. Mice that received a low dose of this virus expressed CTLA4Ig in the serum for an average of 103 days and had a delay in appearance of high titers of anti-DNA antibodies, but this did not result in a better disease outcome compared with untreated controls. In mice treated with high-dose Ad-CTLA4Ig, there was a marked delay in disease onset as assessed by anti-DNA antibody titer, development of fixed proteinuria, histological evidence of renal damage, and survival. These results are similar to those reported by Finck et al. using repeated administration of CTLA4Ig protein (15).

Both murine and human SLE are characterized by early $\mathrm{T}$ cell-independent B-cell hyperreactivity that leads to production of polyclonal IgM antibodies including dsDNA-binding antibodies $(33,34)$. The underlying B-cell hyperreactivity of NZB/NZW F1 mice appeared to be unaffected by CTLA4Ig as evidenced by the persistence of high serum IgM levels and of IgM

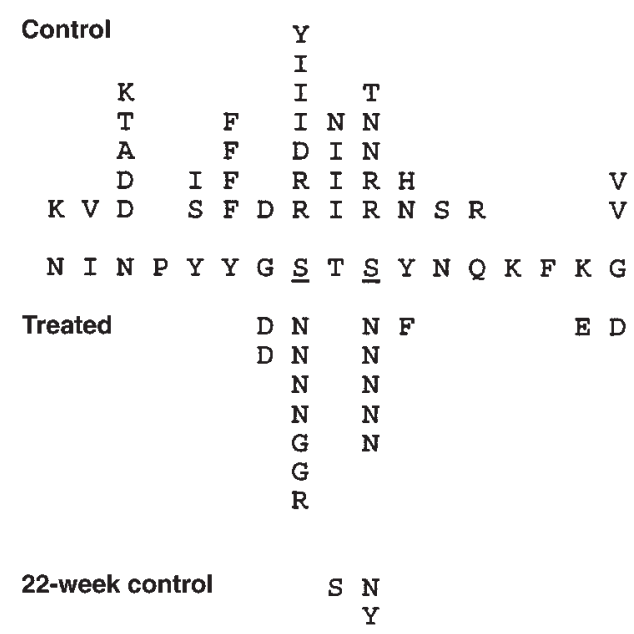

\section{Figure 8}

Pooled mutation analysis of the CDR2 regions of $\mathrm{V}_{\mathrm{H}} \mathrm{BW}-16$ genes from the IgG cDNA libraries compared with the germline sequence. Positions 58 and 60 are underlined. 
anti-DNA antibody-secreting B cells over the course of treatment. In accordance with these observations, there was no alteration of expression of the autoreactive $\mathrm{V}_{\mathrm{H}} \mathrm{BW}-16$ gene in the IgM compartment. However, CTLA4Ig did attenuate the age-related proliferation of cells producing IgM anti-DNA antibodies, suggesting that the activation and proliferation of these cells that are associated with disease onset and progression are costimulation-dependent.

The number of IgG-secreting B cells in the spleens of treated mice was markedly affected by CTLA4Ig treatment. This effect did not occur within the first 8 days; however, in spleens harvested 21 days after treatment, there was a $90 \%$ reduction in the frequency of IgG-secreting cells that was maintained for the duration of treatment. This effect was associated with a block in class switching to IgG. CD28-deficient and CTLA4Ig-transgenic mice have been reported to have a block in class switching associated with decreased serum IgG levels (35, 36). In contrast, serum IgG levels in our AdCTLA4Ig-treated NZB/NZW F1 mice were maintained up to 30 weeks after treatment. Because the frequency of IgG-secreting B cells in the bone marrow was not affected by CTLA4Ig, serum IgG levels in our treated mice may have been maintained by bone marrow plasma cells. These cells are thought to be responsible for maintaining longterm antibody synthesis (37) and appear not to require either T cells or the continuing presence of antigen to survive long term and secrete antibody (38). Alternatively, there may be a subpopulation of B cells that is able to mature and maintain serum IgG levels in the autoimmune background even in the absence of costimulation.

The results of the ELISpot assays further indicated that the decrease in the frequency of $\mathrm{B}$ cells producing IgG anti-DNA antibodies induced by CTLA4Ig was out of proportion to the decrease in overall numbers of IgG-producing B cells. This did not appear to be due to B-cell anergy because we were unable to rescue autoreactive IgG-producing hybridomas from treated mice using the NSO-bcl2 fusion partner, nor could we detect secretion of IgG anti-DNA antibodies in the supernatants of LPS-treated $B$ cells from these mice. These findings suggest either that CTLA4Ig blocks the activation of anti-DNA antibody-producing B cells so that they do not undergo germinal center maturation or that deletion of high-affinity IgG anti-DNA antibody-secreting B cells has occurred.

To distinguish between these possibilities, we performed molecular analysis of the $\mathrm{V}_{\mathrm{H}} \mathrm{BW}-16$ immunoglobulin heavy chain gene that is strongly associated with pathogenic anti-dsDNA antibody activity in SLE-prone mice but is regulated in normal mouse strains $(21,22)$. The development of high-affinity anti-dsDNA antibody activity encoded by $\mathrm{V}_{\mathrm{H}} \mathrm{BW}-16$ in NZB/NZW F1 mice is associated with class switching from IgM to IgG and with the presence of particular amino acids, particularly arginine, in the CDRs of antibodies using this gene (22). We found that although the frequency of $\operatorname{IgM} \mathrm{V}_{\mathrm{H}} \mathrm{BW}-16$ clones was not altered by treatment, there was a decrease in the frequency of $\mathrm{V}_{\mathrm{H}} \mathrm{BW}-16$ clones recovered from IgG cDNA libraries of treated mice compared with controls. Analysis of the IgG $\mathrm{V}_{\mathrm{H}} \mathrm{BW}-16$ clones obtained from the treated mice revealed that related clones were present, as in control mice, and that positive selection of $\mathrm{V}_{\mathrm{H}} \mathrm{BW}-16$ IgG with basic CDR3 regions did not appear to be altered by treatment. There was, however, a $53 \%$ reduction in the frequency of somatic mutation in $\mathrm{V}_{\mathbf{H}} \mathrm{BW}-16 \mathrm{IgG}$ sequences obtained from the treated mice compared with those obtained from the age-matched untreated controls. Subtle differences were also observed in the $\mathrm{V}_{\mathrm{H}} \mathrm{BW}-16$ mutation patterns between treated and control mice; however, it is not possible to know from these experiments whether these differences caused a decrease in the affinity of the expressed antibodies for DNA. In sum, our findings point to a decrease in activation and maturation of IgG $\mathrm{V}_{\mathrm{H}} \mathrm{BW}-16$-encoded antibodies. The decrease in frequency of $\mathrm{V}_{\mathrm{H}} \mathrm{BW}-16$-positive clones in the IgG cDNA libraries and the alterations in mutation patterns might also imply differences in selection of B cells expressing this heavy chain in the treated mice.

FACS ${ }^{\circledR}$ analysis of spleen cells from CTLA4Ig-treated and control NZB/NZW F1 mice revealed that excessive $T$-cell activation was already present in 22-week NZB/NZW F1 mice, and this increased with age. In both groups of treated mice, overexpression of the CD69 activation marker was lost and there was also attenuation of the decrease in CD8-positive T cells. The results in these studies suggest that long-term blockade of the CD28/B7 pathway in the NZB/NZW F1 mouse has a marked negative effect on the numbers of activated $T$ cells. This does not appear to be due to failure of activation of naive T cells, as transition of CD4 $T$ cells from the naive to the memory compartment was not attenuated by Ad-CTLA4Ig treatment. Whether deletion of activated autoreactive $\mathrm{T}$ cells occurred remains to be determined. The decrease in the numbers of activated $\mathrm{T}$ cells may in turn be responsible for the observed effects of CTLA4Ig predominantly on the T cell-dependent steps of B-cell activation.

The failure of CTLA4Ig-treated mice to mount a Tdependent humoral immune response to either the nonreplicating adenoviral vector or, in experiments not shown, to the hapten oxazolone, is consistent with the results just described and shows that continuous treatment with CTLA4Ig is immunosuppressive. We did not challenge the mice with a replicating virus; however, it has previously been reported that CTLA4Ig transgenic mice are able to mount an effective immune response to replicating but not to nonreplicating viruses (39). It remains to be determined whether a there is an optimal dose of CTLA4Ig that will have beneficial effects on autoreactive $\mathrm{T}$ and $\mathrm{B}$ cells without compromising immunity to foreign antigens.

Suppression of anti-DNA antibody production and glomerular disease in the Ad-CTLA4Ig-treated mice appeared to be related to persistence of expression of CTLA4Ig in the serum, as similar effects on both B and $T$ cells were observed both in the low-dose and high- 
dose groups at age 30-36 weeks, but disease became manifest within 2-8 weeks after CTLA4Ig was no longer detected in the serum. Despite the observation that CTLA4Ig can induce tolerance in some transplant models (40), it is striking that CTLA4Ig, even in high dose, did not induce a permanent state of tolerance in NZB/NZW F1 mice.

Our findings are of direct relevance in assessing the potential role of CTLA4Ig in the treatment of B cell-mediated autoimmune diseases in humans. It is likely that in clinical practice, CTLA4Ig will be most effective when it is used in short-term combination with other immunosuppressive reagents (41). It will be of great interest to analyze the safety profile and mechanism of action of CTLA4Ig when used synergistically with anti-CD40L or cyclophosphamide (42) and to determine whether CTLA4Ig will have a steroid-sparing effect. Animal studies in appropriate disease models that lead to better understanding of the specific effects of costimulatory blockade alone or in combination with other immunomodulatory drugs should point the way to more effective and safe treatment for human autoimmune disease.

\section{Acknowledgments}

We thank the Human Genome Project of the Albert Einstein College of Medicine for assistance with preparation of the CTLA4Ig adenovirus, D. Gebhard for assistance with FACS ${ }^{\circledR}$ analysis, C. Grimaldi for mouse $\mathrm{VH}$ and $\mathrm{VL}$ primers, $\mathrm{M}$. Zhang for testing of the $\mathrm{V}_{\mathrm{H}} \mathrm{BW}$ 16 oligomers, and $\mathrm{C}$. Wang for assistance with the glomerular binding assays. We thank B. Diamond, N. Green, H. Keiser, and C. Putterman for critical reading of the manuscript. This work was supported by the American Heart Association, the NY Community Trust and the NY SLE Foundation.

1. Raz, E., Brezis, M., Rosenmann, E., and Eilat, D. 1989. Anti-DNA antibodies bind directly to renal antigens and induce kidney dysfunction in the isolated perfused rat kidney. J. Immunol. 142:3076-3082.

2. Diamond, B., et al. 1992. The role of somatic mutation in pathogenic anti-DNA antibodies. Annu. Rev. Immunol. 10:731-757.

3. Reiser, H., and Stadecker, M.J. 1996. Costimulatory B7 molecules in the pathogenesis of infectious and autoimmune diseases. N. Engl. J. Med. 335:1369-1377.

4. Lederman, S., et al. 1996. T lymphocyte mediated differentiation of B lymphocytes: the central role of the CD40-ligand:CD40 pathway. Curr. Opin. Hematol. 3:77-86.

5. Wofsy, D., and Daikh, D.I. 1998. Opportunities for future biological therapy in SLE. Baillieres Clin. Rheumatol. 12:529-541.

6. Grewal, I.S., and Flavell, R.A. 1998. CD40 and CD154 in cell-mediated immunity. Annu. Rev. Immunol. 16:111-135.

7. Lindhout, E., Koopman, G., Pals, S.T., and de Groot, C. 1997. Triple check for antigen specificity of B cells during germinal centre reactions. Immunol. Today. 18:573-577.

8. Tarlinton, D. 1998. Germinal centers: form and function. Curr. Opin. Immunol. 10:245-251.

9. Mamula, M.J. 1998. Epitope spreading: the role of self peptides and autoantigen processing by B lymphocytes. Immunol. Rev. 164:231-239.

10. Chan, O., and Shlomchik, M.J. 1998. A new role for B cells in systemic autoimmunity: B cells promote spontaneous $\mathrm{T}$ cell activation in MRLlpr/lpr mice. J. Immunol. 160:51-59.

11. Sayegh, M.H. 1999. Finally, CTLA4Ig graduates to the clinic. J. Clin. Invest. 103:1223-1225.

12. Linsley, P.S., et al. 1994. Human B7-1 (CD80) and B7-2 (CD86) bind with similar avidities but distinct kinetics to CD28 and CTLA-4 receptors. Immunity. 1:793-801.

13. Abrams, J.R., et al. 1999. CTLA4Ig-mediated blockade of T-cell costimulation in patients with psoriasis vulgaris. J. Clin. Invest. 103:1243-1252.
14. Guinan, E.C., et al. 1999. Transplantation of anergic histoincompatible bone marrow allografts. N. Engl. J. Med. 340:1704-1714.

15. Finck, B.K., Linsley, P.S., and Wofsy, D. 1994. Treatment of murine lupus with CTLA4Ig. Science. 265:1225-1227.

16. Ilan, Y., et al. 1998. Oral tolerization to adenoviral proteins permits repeated adenovirus-mediated gene therapy in rats with pre-existing immunity to adenoviruses. Hepatology. 27:1368-1376.

17. Ray, S., and Diamond, B. 1994. Generation of a fusion partner to sample the repertoire of splenic B cells destined for apoptosis. Proc. Natl. Acad. Sci. USA. 91:5558-5551.

18. Nieto, A., Gaya, A., Jansa, M., Moreno, C., and Vines, J. 1984. Direct measurement of antibody affinity distribution by hapten-inhibition enzyme immunoassay. Mol. Immunol. 21:537-543.

19. Kuo, P., Alban, A., Gebhard, D., and Diamond, B. 1997. Overexpression of $b c l$-2 alters usage of mutational hot spots in germinal center B cells. Mol. Immunol. 34:1011-1018.

20. Li, S.C., et al. 1994. Expression of $1 \mu-\mathrm{C} \gamma$ hybrid germline transcripts subsequent to immunoglobulin heavy chain class switching. Int. Immunol. 6:491-497.

21. Ash-Lerner, A., et al. 1997. Expression of an anti-DNA-associated $V_{\mathrm{H}}$ gene in immunized and autoimmune mice. J. Immunol. 159:1508-1519.

22. Katz, M.S., Foster, M.H., and Madaio, M.P. 1993. Independently derived murine glomerular immune deposit-forming anti-DNA antibodies are encoded by near-identical $V_{\mathrm{H}}$ gene sequences. J. Clin. Invest. 91:402-408.

23. Zylstra, P., Rothenfluh, H.S., Weiller, G.F., Blanden, R.V., and Steele, E.J. 1998. PCR amplification of murine immunoglobulin germline $V$ genes: strategies for minimization of recombination artefacts. Immunol. Cell. Biol. 76:395-405.

24. Neuberger, M.S., et al. 1998. Monitoring and interpreting the intrinsic features of somatic mutation. Immunol. Rev. 162:107-116.

25. Bradley, L.M., Croft, M., and Swain, S.L. 1993. T cell memory: new perspectives. Immunol. Today. 14:197-199.

26. Budhai, L., Oh, K., and Davidson, A. 1996. An in vitro assay for detection of glomerular binding IgG autoantibodies in patients with SLE. J. Clin. Invest. 98:1585-1593.

27. Krishnan, M.R., Jou, N.T., and Marion, T.N. 1996. Correlation between the amino acid position of arginine in VH-CDR3 and specificity for native DNA among autoimmune antibodies. J. Immunol. 157:2430-2439.

28. Theofilopoulos, A.N., and Dixon, F.J. 1985. Murine models of systemic lupus erythematosus. Adv. Immunol. 37:269-390.

29. Ando, D.G., Sercarz, E.E., and Hahn, B.H. 1987. Mechanisms of T and B cell collaboration in the in vitro production of anti-DNA antibodies in the NZB/NZW F 1 murine SLE model. J. Immunol. 138:3185-3190.

30. Sekigawa, I., et al. 1987. Class-specific regulation of anti-DNA antibody synthesis and the age-associated changes in $(\mathrm{NZB} \times \mathrm{NZW}) \mathrm{F}_{1}$ hybrid mice. J. Immunol. 138:2890-2895.

31. Sato, M.N., Minoprio, P., Avrameas, S., and Ternynck, T. 1995. Defects in the regulation of anti-DNA antibody production in aged lupus-prone (NZB x NZW) F 1 mice: analysis of T-cell lymphokine synthesis. Immunology. 85:26-32.

32. Datta, S.K., Patel, H., and Berry, D. 1987. Induction of a cationic shift in IgG anti-DNA autoantibodies. J. Exp. Med. 165:1252-1268.

33. Reininger, L., et al. 1996. Intrinsic B cell defects in NZB and NZW mice contribute to systemic lupus erythematosus in (NZB X NZW)F1 mice. J. Exp. Med. 184:853-861.

34. Mihara, M., et al. 1988. Immunologic abnormality in NZB/NZW F1 mice. Thymus-independent occurrence of B cell abnormality and requirement for $\mathrm{T}$ cells in the development of autoimmune disease, as evidenced by an analysis of the athymic nude individuals. J. Immunol. 141:85-90.

35. Lane, P., et al. 1994. B cell function in mice transgenic for mCTLA4-H gamma 1: lack of germinal centers correlated with poor affinity maturation and class switching despite normal priming of CD4+ T cells. $J$. Exp. Med. 179:819-830.

36. Green, J.M., et al. 1994. Absence of B7-dependent responses in CD28deficient mice. Immunity. 1:501-508.

37. Slifka, M.K., Antia, R., Whitmire, J.K., and Ahmed, R. 1998. Humoral immunity due to long-lived plasma cells. Immunity. 8:363-372.

38. Manz, R.A., Lohning, M., Cassese, G., Thiel, A., and Radbruch, A. 1998. Survival of long-lived plasma cells is independent of antigen. Int. Immunol. 10:1703-1711.

39. Zimmermann, C., Seiler, P., Lane, P., and Zinkernagel, R.M. 1997. Antiviral immune responses in CTLA4 transgenic mice. J. Virol. 71:1802-1807.

40. Schaub, M., Stadlbauer, T.H.W., and Sayegh, M.H. 1997. CTLA4Ig: effects on cellular and humoral immunity and macrophage activation. Exp. Nephrol. 5:370-374.

41. Daikh, D.I., Finck, B.K., Linsley, P.S., Hollenbaugh, D., and Wofsy, D. 1997. Long-term inhibition of murine lupus by brief simultaneous blockade of the B7/CD28 and CD40/gp39 costimulation pathways. $J$. Immunol. 159:3104-3108.

42. Cunnane, G., et al. 1999. Effects of combined CTLA4Ig and cyclophosphamide on renal pathology in advanced murine lupus. Arthritis Rheum. 42:S359. (Abstr.) 